\title{
Article
}

\section{A time and a place: A framework for caffeine periodization throughout the sporting year}

Pickering, Craig and Grgic, Jozo

Available at http://clok.uclan.ac.uk/36108/

Pickering, Craig and Grgic, Jozo (2020) A time and a place: A framework for caffeine periodization throughout the sporting year. Nutrition . p. 111046. ISSN 0899-9007

It is advisable to refer to the publisher's version if you intend to cite from the work. http://dx.doi.org/10.1016/j.nut.2020.111046

For more information about UCLan's research in this area go to http://www.uclan.ac.uk/researchgroups/ and search for < name of research Group>.

For information about Research generally at UCLan please go to http://www.uclan.ac.uk/research/

All outputs in CLoK are protected by Intellectual Property Rights law, including Copyright law. Copyright, IPR and Moral Rights for the works on this site are retained by the individual authors and/or other copyright owners. Terms and conditions for use of this material are defined in the policies page. 
1 Title: A time and a place: a framework for caffeine periodization throughout the sporting year.

2

3 Running Head: Caffeine periodization

4

5 Submission Type: Review Article

6

7 Authors: Craig Pickering ${ }^{1}$, Jozo Grgic ${ }^{2}$

8

9

10

1. Institute of Coaching and Performance, School of Sport and Wellbeing, University of Central Lancashire, Preston, UK

12

13 Corresponding Author:

14 Craig Pickering

15 Institute of Coaching and Performance, School of Sport and Wellbeing, University of Central Lancashire, Fylde

16 Road, Preston, PR1 2HE, UK.

17 Email: craigpickering1014@ hotmail.com

18

19

20

21

22

23

24

25

26

27

28

29

30 


\section{Abstract}

35 Caffeine is a well-established ergogenic aid, with its performance-enhancing effects demonstrated across a variety of sports and exercise types. As a result of caffeine's ergogenic properties, it is widely utilised by athletes at all levels around both competition and training. Caffeine exerts its performance benefits through a variety of mechanisms, each of which may be of increased importance at a given stage of training or competition. In addition, regular caffeine use may diminish the performance enhancing effects of a subsequent dose of caffeine. Recently, interest in the concept of nutritional periodization has grown; here we propose a framework for the periodization of caffeine through the sporting year, balancing its training and competition performance-enhancing effects, along with the need to mitigate any negative effects of habituation.

43 Furthermore, the regular use of caffeine within training may support the development of positive beliefs towards caffeine by athletes — potentially serving to enhance future performance through placebo and expectancy mechanisms - as well as allowing for the optimisation of individual athlete caffeine strategies. Whilst future work is required to validate some of the suggestions made, the framework proposed here represents a starting point for athletes to maximise caffeine's performance benefits across the sporting year. 


\section{Introduction - The ever-broadening role of periodization in sport and exercise.}

63 Sports coaches have long understood the inherent value within the concept of periodization, broadly defined as the systematic planning of long- and short-term training programs aimed at optimising performance-relevant adaptations [1,2]. Whilst the underpinning scientific rationale [3] and study methodologies [4] suggests that traditional periodization concepts are not the panacea they are often held up to be, there is clear evidence that variation in imposed training demands can enhance performance [1]. Whilst previously limited to the exercise domain, the concept of periodization has expanded, with the underlying principles explored within altitude training [5], body composition [6], heat adaptation [7], recovery [1], and psychological skills [1]. One area in which periodization principles are of increased interest is sports nutrition [1-2, 8-10], with periodized nutrition defined as "the planned, purposeful, and strategic use of specific nutritional interventions to enhance the adaptations targeted by individual exercise sessions or periodic training plans, or to obtain other effects that will enhance performance longer term" [9]. Periodized nutrition has been primarily studied in terms of carbohydrate utilisation within aerobic endurance athletes, whereby carbohydrate availability is manipulated to drive desired molecular and physiological adaptations to exercise $[8,10]$. Interest in nutritional periodization techniques has grown, with the principles applied to strength athletes [2], and a general framework in the scientific literature has been recently proposed [10]. Here, we expand the concept of nutritional periodization by applying it to caffeine, a widely-used, effective ergogenic aid [11], exploring how manipulation of caffeine's use may support athlete performance across the training year.

\section{Caffeine - a potent performance enhancer}

Caffeine (1,3,7-trimethylxanthine) is a popular ergogenic substance, widely utilised by athletes [12] and nonathletes [13] alike. The performance-enhancing effects of caffeine have long been established, with the first known study exploring caffeine's use during exercise published over 100 years ago [14]. A recent umbrella review [11] reported a clear ergogenic effect of caffeine on muscle strength, muscular endurance, anaerobic power, and aerobic endurance. Whilst caffeine has significant acute ergogenic effects [11], it also has wider effects that are currently underexplored within sporting contexts. For example, caffeine has the potential to significantly harm sleep [15], but may also enhance post-exercise glycogen recovery [16]. Across a training 
91 Delayed Onset of Muscle Soreness (DOMS) [17], mitigate feelings of fatigue [18], and potentially even enhance specific training adaptations [19]. However, regular caffeine use may reduce the subsequent ergogenic effects of a given caffeine dose [20,21]. As such, there is a clear scope for exploring the structured, periodized use of caffeine across the training year, with caffeine utilized to support performance or specific adaptations at a given time, and exposure varied to guard against possible habituation. Whilst much of the focus in research is directed towards exploring acute ergogenic effects of caffeine on different exercise tasks, such data provide little insight into methods that can be utilized by athletes interested in long-term supplementation with caffeine. In this manuscript, the first to our knowledge to examine caffeine in this way, we discuss how caffeine intake might be periodized across the training and competitive year, and provide some tentative recommendations to athletes, coaches and practitioners who are interested in getting the most out of their caffeine supplementation practices.

101

\section{Caffeine use in sport - a time and a place?}

103

\subsection{Acute Caffeine Use - Implications for Training \& Competition}

105

106 Caffeine's performance-enhancing effects are well-established and well-replicated, and are overwhelmingly

107 acute in nature [11]. Evidence suggests that caffeine enhances aerobic endurance [22], high-intensity efforts

108 [23], muscular endurance [24], sprint performance [25], and maximum strength [26]. Caffeine also acutely

109 enhances sporting performance, with ergogenic effects of caffeine on sport-specific endurance [27], power-

110 based sports [28], as well as performance in volleyball [29], rugby [30], soccer [31], basketball [32], and

111 swimming [33]. Given these broad ergogenic effects - both in terms of general physical abilities and sport-

112 specific performance - caffeine itself is widely utilised by sportspeople, with research suggesting that 75-90\%

113 of athletes consume caffeine prior to, or during, competition [34,35].

115 Caffeine also has the potential to exert other beneficial effects that may enhance acute sporting performance,

116 such as enhancing cognitive performance [36] — especially when sleep-restricted [37]—and mood, supporting

117 sporting performance when sleep deprived [38], enhancing skill execution [39], and reducing sensations of pain

118 and soreness [40]. Given these benefits, caffeine is widely utilised by athletes as performance-enhancer at

119 different stages of the sporting year. 


\subsubsection{Caffeine use in competition}

122 During the competition phase of the sporting year, the athlete is focused first and foremost on enhancing

123 physical performance. Given caffeine's ergogenic effects, it would appear sensible to recommend that athletes

124 utilise caffeine either directly before, or during, competition. There are, however, some side effects to be aware

125 of. Caffeine has the potential to increase feelings of anxiety [41]. Increased anxiety can be positive if the athlete

126 requires an increase in arousal pre-competition, but may become performance-limiting prior to competitions

127 when the athletes arousal and anxiety levels are already high, such as the Olympic Games [42]. Additionally,

128 because caffeine has strong stimulant properties, it can increase sleep latency and decrease sleep quality [15,43].

129 Whilst caffeine's stimulant effects may be positive during competition due to increased performance and

130 wakefulness - especially if the athlete is jet lagged — it also seems that caffeine has the ability to significantly

131 harm post-competition recovery. Clearly, a pragmatic approach would be required here; is the subsequent loss

132 of sleep and impaired recovery a worthwhile price to pay for enhanced competition performance? Many athletes

133 would likely argue that it is, although further research is required to understand how this might affect

134 competitive bouts in close duration—in terms of days—-such as within a sporting championship $[44,45]$.

135

136 Another area where caffeine ingestion may be beneficial is within repeated competitive bouts that occur on the

137 same day $[44,45]$. For example, at the recent 2019 World Athletics Championships, the semi-finals and finals of

138 the women's 100m were separated by just 2 hours. A number of issues here require further elucidation; if the

139 second competitive bout takes place within a period of time in which plasma caffeine concentrations are

140 maintained, what effect—if any — does a secondary caffeine dose have? Does the increased work rate afforded

141 by caffeine supplementation [46] cause increased fatigue and/or muscle damage that may harm a subsequent

142 performance bout? An initial study [47] demonstrated no negative effect of caffeine supplementation on

143 exercise bouts on consecutive days, and Bell and McLellan [48] reported that $6 \mathrm{mg} / \mathrm{kg}$ of caffeine consumed

144 prior to an exercise bout still exerted an ergogenic effect on a second exercise bout taking place 6 hours later,

145 with no additional performance-enhancement with a second dose of caffeine $(2.5 \mathrm{mg} / \mathrm{kg})$. Conversely, Negaresh

146 and colleagues [49] reported increased efficacy of repeated dosing (5x) of caffeine at $2 \mathrm{mg} / \mathrm{kg}$ compared to a

147 single caffeine dose $(10 \mathrm{mg} / \mathrm{kg})$ during a wrestling tournament of multiple competitive bouts. As future research

148 allows us to better understand the influence of repeated competitive bouts on caffeine ergogenicity, more

149 targeted guidelines may be developed. 
152 During the general training phase —often termed the "off-season"- the athlete is focused on building

153 performance capacity through the accumulation of training volume (i.e. total workload) and/or intensity (i.e.

154 effort or load). As detailed above, caffeine is a potent performance enhancer [11], which is why athletes utilise

155 caffeine prior to competition. However, caffeine's acute ergogenic effects will also enhance performance in

156 individual training sessions; as a result, athletes also use caffeine pre-training as a performance enhancer [50].

157 However, caffeine supplementation during training phases may be efficacious for a variety of further reasons.

158 Research suggests that caffeine may attenuate post-exercise DOMS and perception of soreness [51,52], and

159 caffeine can enhance mood and alertness [53], as well as alleviate feelings of fatigue that may be associated

160 with increased training loads [51] and the lack of sleep often associated with early morning training sessions

161 [38]. Caffeine has also been shown to alleviate mental fatigue, enhancing endurance [54] and skill [36]

162 performance. There is the potential that caffeine may enhance post-exercise recovery, with some data suggesting

163 that caffeine, and other ingredients in coffee such as cafestol and caffeic acid, may enhance muscle glycogen

164 recovery [16]. Finally, when an athlete is experiencing soreness in the form of DOMS, caffeine appears to

165 mitigate the pain associated with subsequent exercise [17], enhancing performance within the subsequent

166 training session.

167

168 Can caffeine enhance training adaptations?

169 Caffeine primarily serves to acutely enhance exercise performance, with its effects typically only lasting for 3-4

170 hours [55]. However, if caffeine acutely enhances performance in individual training sessions, do these acute

171 increases combine to deliver greater adaptations to the training program as a whole, when compared to athletes

172 who do not utilise caffeine supplementation [44]? Very few studies have explored this; however, Malek and

173 colleagues [56] randomised subjects to receive either a placebo or caffeine-containing supplement (201mg of

174 caffeine) prior to each training session within an 8-week aerobic training program, with no significant

175 differences in peak oxygen consumption reported between the groups. In another study, participants performed

176 resistance training three times per week for six weeks [57]. One group ingested $3 \mathrm{mg} / \mathrm{kg}$ caffeine 60-minutes

177 before each session, whilst the other ingested a placebo. After six weeks, both groups increased maximum

178 strength in the bench press and squat; however, the improvement was greater in the caffeine ingestion group.

179 This group also had a higher volume load (sets $\mathrm{x}$ load $\mathrm{x}$ repetitions), suggesting that long-term improvements in

180 strength are likely explained by acute improvements in exercise performance following caffeine ingestion 
181 before every session. Whilst this study requires replication, the results suggest that regular pre-exercise caffeine

182 ingestion may enhance training adaptations.

183

184 Caffeine may modify the molecular signals that occur post-exercise. At supraphysiological doses (e.g. $5 \mathrm{mM}$ ),

185 caffeine appears to inhibit mammalian target of rapamycin (mTOR) - a key intracellular enzyme associated

186 with resistance exercise-induced muscle hypertrophy - activity [58,59], although these results are equivocal

187 when physiological levels (e.g. $0.3 \mathrm{mM}$ ) of caffeine are applied [60]. To our knowledge, there are only

188 unpublished observations examining the acute effects of caffeine on anabolic signaling in humans. Here,

189 caffeine intake prior to resistance exercise did not have any effect on p70S6 kinase or muscle protein synthesis

190 following exercise, possibly because the study also did not find an overall ergogenic effect on caffeine on

191 performance [61]. Similarly, prolonged exposure of muscle cells to high concentrations of caffeine appears to

192 enhance mitochondrial biogenesis [62], although further research is required to explore the effects of caffeine,

193 when consumed as an ergogenic aid, on various muscle signaling pathways. Nevertheless, caffeine has a

194 theoretical ability to enhance training adaptations in athletes, either by increasing workload or augmenting post-

195 exercise adaptive signaling, although substantially more research in humans is required in this area.

196

$197 \quad 3.2$ Chronic Caffeine Use - A need for periodization?

\subsubsection{Habituation}

200 Regular exposure to caffeine is associated with physiological adaptations that may reduce its future ergogenic 201 effects $[63,64]$. As a result, caffeine habituation is often reported as a potential modifying factor of the acute response to caffeine $[21,42,64]$, although there are a surprisingly small number of studies exploring the influence of caffeine habituation on exercise performance, with conflicting findings reported [20,44]. In general, studies either report no negative influence of regular caffeine intake on its subsequent ergogenic effects [65-67], or a reduced—but not eliminated—subsequent ergogenic effect $[21,68,69]$. The specific mechanisms driving this loss of ergogenic effects with regular use are poorly understood, but may include increased metabolisation speed, along with increased adenosine receptor densities [20].

209 If regular caffeine use blunts the subsequent ergogenic effects of caffeine, then there are some potential strategies athletes could utilise to ensure they derive the maximum benefit from caffeine supplementation at the 
211 time it matters most-prior to competition. Short-term caffeine withdrawal has been proposed as a method of

212 becoming re-sensitised to caffeine's ergogenic effects [70], which again has been relatively poorly studied [20].

213 In studies conducted on this topic, short-term (i.e. 4 day) caffeine withdrawal did not significantly improve the

214 subsequent ergogenic effects of a dose of caffeine [71,72]. Longer periods of caffeine withdrawal have not, to

215 our knowledge, been studied; furthermore, short-term caffeine withdrawal is associated with negative side

216 effects such as fatigue, irritability, muscle pain, sleep disturbances, and nausea [72-74]. From a biological basis,

217 this caffeine dependence is proposed to be because of the increased functional sensitivity to endogenous

218 adenosine [74]. Whilst typically mild, and reversible upon caffeine ingestion [55,75], such sensations are likely

219 to be undesirable in elite athletes prior to competition.

220

221 A second potential option is for athletes to consume a greater pre-competition dose of caffeine relative to their

222 habitual, pre-training and daily life caffeine intakes [20]. This pragmatic approach, which balances the daily,

223 non-sporting consumption of caffeine (primarily via caffeinated beverages such as coffee) and the targeted pre-

224 training use of caffeine widely utilised by athletes [50] with the need to maintain an optimised ergogenic

225 response to caffeine pre-competition [20]. In this case, regular consumption of low-to-moderate doses of

226 caffeine $(\sim 2-3 \mathrm{mg} / \mathrm{kg} / \mathrm{d})$ and a pre-competition caffeine dose of $\sim 4-5 \mathrm{mg} / \mathrm{kg}$ would likely suffice, although there

227 is considerable inter-individual variation in the optimal caffeine dose, and this approach has not yet been studied

228 in the literature $[20,42]$.

\subsubsection{Building beliefs}

231 A small number of studies have demonstrated the effectiveness of placebo caffeine in enhancing performance

232 [76-80], such that, if an athlete believes they have consumed caffeine, and they believe that caffeine is

233 ergogenic, they likely will experience an ergogenic effect following caffeine supplementation, regardless of

234 whether caffeine has been consumed. As a result, cultivating a belief in the ergogenic effects of caffeine, and the

235 athlete recognising - through taste or physical sensations - that caffeine has been consumed, may be important

236 in maximising the ergogenic response to a pre-competition caffeine dose. Regular caffeine intake may therefore

237 be important in allowing the athlete to both have positive prior experiences following caffeine ingestion, as well

238 as recognise the taste, and other physiological responses, associated with caffeine $[81,82]$. Finally, ritualistic

239 behaviour — such as consuming caffeine in a set routine and method—supports positive outcomes of placebo 
240 [83]. As such, the regular consumption of caffeine, as part of a pre-training routine, may support ergogenic

241 effects when caffeine is consumed prior to competition.

\subsubsection{Optimising individual practice}

244 Whilst there are well-established guidelines suggesting that ingestion of 3-6 mg/kg of caffeine, consumed around 60-minutes prior to exercise, is ergogenic [84], there is considerable variation in both the optimal caffeine dose, and the timing of that dose, between individuals [42]. This individual response appears to occur due to genetic variation between individuals (for example, a common polymorphism (i.e. genetic variation) within CYP1A2 appears to influence caffeine ergogenicity [85], although the findings on this topic are equivocal [86,87]), along with common environment differences such as habitual caffeine use [21,68-71], age [88], time of day [89-91], training status [89,92], along with caffeine-related beliefs and expectancy [76,79]. As a result, developing an optimised caffeine strategy for individual athletes may require considerable trial and error [42]; by experimenting with caffeine during training periods, athletes can perhaps better develop and refine their precompetition caffeine strategies, increasing their confidence of success on the day of competition.

\section{Practical Implications - Building a caffeine periodization framework}

As detailed above, caffeine has clear and well-established performance enhancing effects [11], and, as a result, it is widely used by athletes in training and competition alike $[12,50]$. The regular use of caffeine during prolonged training phases may lead to caffeine habituation and reduced subsequent ergogenic effects [21,68], although this finding is equivocal [66]. If long-term caffeine ingestion indeed attenuates its ergogenic potential, this adaptation may suggest that athletes might be unable to maximally harness caffeine's ergogenic effects during the competition period. One way to potentially mitigate these effects is to avoid caffeine use during training periods; however, doing so may:

a) Harm performance during individual training sessions, either directly through physiological changes, or by influencing mood and/or perception of effort;

b) Minimise the time available for self-experimentation of optimised caffeine strategies;

c) Minimise the athlete's exposure to caffeine, potentially reducing the capacity of that athlete to build positive beliefs around caffeine use pre-exercise. 
270 Accordingly, it appears that athletes and their support staff-including the coach, sports nutritionist, or

271 Registered Dietician — should balance the use of caffeine across the training year using the principles of

272 periodization (i.e. the use of strategic temporal nutritional interventions in line with the training demands and

273 required adaptations across days [microcycles], weeks [mesocyles], and months [macrocyles] [10]), with the

274 positive and negative adaptations expected following regular caffeine use outlined within this article.

275

276

277

278

279

280

281

282

283

284

285

286

287

288

289

290

291

292

293

294

295

296

297

298

299

In their recent paper, Stellingwerff and colleagues [10] developed a framework for the periodization of nutrition, in which nutritional interventions are utilised to support the bridging of performance gaps in athletes across macro-, meso-, and microcycles in a strategic manner. As an example, for an elite middle distance athlete preparing for the Olympic Games, the training year could (very broadly) be broken up into an accumulation phase, in which the athlete accumulates lower-intensity aerobic training volumes interspersed with less frequent high-intensity anaerobic training sessions, followed by an intensification phase, in which the relative volume of low intensity training decreases, and high intensity training increases, followed by the competition phrase. Each phrase may also be punctuated by training camps and periods of travel, potentially involving the crossing of multiple time zones.

During the accumulation phase, the aim would be to keep overall daily caffeine intake sufficiently low to mitigate long-term habituation affecting the pre-competition caffeine dose [20]. Therefore, in this phase, the athlete may decide to consume lower doses of caffeine $(<3 \mathrm{mg} / \mathrm{kg})$ before and during their longer sessions, targeted to mitigate sensations of physiological and psychological fatigue [93,94]. Prior to higher intensity sessions, the athlete may decide to consume a relatively greater dose of caffeine $(\sim 3 \mathrm{mg} / \mathrm{kg})$ to optimise performance in their "key" sessions, and mediate some of the general fatigue and soreness that may be accumulating [24,51]. Caffeine may also be utilised to augment other nutritional interventions, such as training with low carbohydrate availability $[95,96]$; here, caffeine may support performance when training a carbohydrate-depleted state $[97,98]$.

As the athlete gets closer to the competition period, they may begin restricting energy intake as a means of reducing body fat and enhancing power-to-weight ratio [95]; during this period, caffeine ingestion may again alleviate feelings of fatigue [18], and, when consumed before a meal, may suppress acute energy intake [99]. Middle-distance runners may also utilise periods of altitude exposure to drive favourable physiological 
301 prior to training may support performance [100] and hence drive positive training adaptations. Depending on

302 their home base, athletes may have to travel across multiple time zones for both training camps and

303 competitions, becoming subjected to both travel fatigue and jet lag. Caffeine has been demonstrated to be

304 effective in mitigating daytime sleepiness following trans-meridian travel [101], and so its use may support

305 subsequent performance in athletes following travel. During this phase of training, the athlete may wish to

306 undergo some caffeine strategy self-experimentation prior to sessions that most mimic the competitive demands,

307 varying caffeine dose, timing, and source to optimise performance [42,102,103].

309 During the competition period, athletes will primarily be utilising caffeine as a means of enhancing their

310 competition performance. The use of caffeine in this way is subject to nuance, including consideration of:

311 a) Whether the dose of caffeine is sufficient to both mitigate any negative effects of habituation and deliver an optimised performance benefit [20, 104]; from a pragmatic perspective, during competition the athlete should utilise a caffeine dose that provides the greatest ergogenic effect whilst simultaneously being tolerable in terms of side-effects.

b) The state of arousal and/or anxiety of the athlete, with caffeine having the potential to increase both [41], potentially harming performance.

c) The contexts of the current competition; does the athlete have a more important competition or

\subsection{Caffeine Source}

There are a variety of ways by which athletes could consume caffeine before and during both training and competition, including through caffeine anhydrous, sports drinks, energy drinks, carbohydrate bars and gels, gum, and coffee $[103,107]$. Coffee is likely a poor way to obtain caffeine pre-exercise; it exhibits substantial variation in caffeine concentrations both between brands/brews, but also within the same brand/brew across time [108-110]. As such, it can be difficult to accurately quantify the dose of caffeine consumed, which, given 
the potential for under- and over-dosing, increases the risk of making an error. Additionally, coffee tends to be consumed hot [107], which may harm performance in hot environments, and coffee also has the potential to be a gastric irritant [111]. Furthermore, a large volume of coffee may be required to deliver an ergogenic dose of caffeine, which may increase feelings of fullness and discomfort [107]. Due to these limitations, coffee might be an option for caffeine supplementation in the accumulation and intensification phases. However, given the importance of competition, athletes should seek to ensure that, during the competition phase, caffeine is obtained through a medium with limited dose variability, such as caffeine anhydrous, although other forms of caffeine supplementation, including with additional ergogenic substances such as carbohydrates, may be useful [103]. Caffeine sources and supplements with limited dose variability may also be useful during the regular training phases as a way of tightly monitoring caffeine intake.

\section{Conclusion}

343 As outlined within this manuscript, caffeine is a potent and well-established ergogenic substance [11], used

344 regularly by athletes around both training [50] and competition [12]. Caffeine has a broad mechanism of action, and elicits its ergogenic effects through a variety of supplementation approaches; knowledge of these

346 approaches can lead to a more nuanced use of caffeine to support specific outcomes across the sporting year.

347 Maintenance of caffeine's ergogenic effects during competition is crucial [20], and so caffeine should be utilised

348 in training in a way that maintains those benefits, possibly through limiting the habitual intake of caffeine to around $3 \mathrm{mg} / \mathrm{kg}$ per day, and utilising larger doses prior to competition [20]. During training phases, more moderate caffeine doses (1-3 mg/kg) can be used to acutely support performance during key sessions, and minimise attenuation of caffeine's ergogenic effects associated with chronic caffeine ingestion. Hypothetically, this approach would maximise performance benefits from acute caffeine ingestion at the competition.

354 The use of caffeine always comes at a cost, be that a gradual reduction in ergogenic response to a given dose [21], increased muscle damage and soreness due to enhanced workload [47], or reduced recovery due to sleep disturbances [15], or, in some cases, attenuated effectiveness of other consumed supplements [112]. In contrast, by not utilising caffeine, athlete performance may be lower than what is possible in both competition and training, and, in the latter case, this may reduce the magnitude of adaptations accumulated during a training 
360 performance whilst reducing any negative outcomes associated with its use — commonly termed "nutritional

361 periodization"-represents perhaps the best approach to caffeine use over time. As we better understand some

362 of the nuance around regular caffeine use, including the question of habituation, the effect on repeated

363 competitive bouts, and training adaptations [20,44,45], we will be better able to provide more tailored advice. In

364 the meantime, we encourage coaches, athletes, and their support staff to consider three key questions:

a) What am I hoping to achieve in this particular session or competition?

b) How might the use of caffeine support me in achieving these goals?

c) What are the potential costs of utilising caffeine during this session or competition, and how can I mitigate these side-effects?

In doing so, we hope that caffeine's ergogenic effects can be optimized by all, supporting the athlete in their performance goals.

371

372 Compliance with Ethical Standards

373 Funding

374 No sources of funding were used to assist in the preparation of this article.

375 Conflicts of Interest

376 Craig Pickering and Jozo Grgic declares that they have no conflict of interest relevant to the content of this 377 article.

378 Author Contributions

379 CP: Conceptualization, Writing - original draft

380 JG: Writing - review \& editing

1. Mujika I, Halson S, Burke LM, Balagué G, Farrow D. An integrated, multifactorial approach to periodization for optimal performance in individual and team sports. Int J Sports Physiol Perform. 2018;13(5):538-61.

2. Mota JA, Nuckols G, Smith-Ryan AE. Nutritional periodization: Applications for the strength athlete. Strength Cond J. 2019;41(5):69-78.

3. Kiely J. Periodization theory: confronting an inconvenient truth. Sports Med. 2018;48(4):753-64. 
4. Afonso J, Rocha T, Nikolaidis PT, Clemente FM, Rosemann T, Knechtle B. A systematic review of meta-analyses comparing periodized and non-periodized exercise programs: Why we should go back to original research. Front Physiol. 2019;10:1023.

5. Mujika I, Sharma AP, Stellingwerff T. Contemporary periodization of altitude training for elite endurance athletes: a narrative review. Sports Med. 2019;49(11):1651-1669..

6. Stellingwerff T. Case study: Body composition periodization in an Olympic-level female middledistance runner over a 9-year career. Int J Sport Nutr Exerc Metab. 2018;28(4):428-33.

7. Casadio JR, Kilding AE, Cotter JD, Laursen PB. From lab to real world: heat acclimation considerations for elite athletes. Sports Med. 2017;47(8):1467-76.

8. Marquet LA, Hausswirth C, Molle O, Hawley J, Burke L, Tiollier E, Brisswalter J. Periodization of carbohydrate intake: Short-term effect on performance. Nutrients. 2016;8(12):755.

9. Jeukendrup AE. Periodized nutrition for athletes. Sports Med. 2017;47(1):51-63.

10. Stellingwerff T, Morton JP, Burke LM. A framework for periodized nutrition for athletics. Int J Sport Nutr Exerc Metab. 2019;29(2):141-51

405

406

407

408

409

410

411

412

413

414

415

416

417

418

419

420

421

422

423

424

425

426

427

428

429

430
11. Grgic J, Grgic I, Pickering C, Schoenfeld BJ, Bishop DJ, Pedisic Z. Wake up and smell the coffee: Caffeine supplementation and exercise performance-An umbrella review of 21 published metaanalyses. Br J Sports Med. 2019;54(11):681-688.

12. Aguilar-Navarro M, Muñoz G, Salinero JJ, Muñoz-Guerra J, Fernández-Álvarez M, Plata MD, Del Coso J. Urine caffeine concentration in doping control samples from 2004 to 2015. Nutrients. 2019;11(2):286.

13. Heckman MA, Weil J, De Mejia EG. Caffeine (1, 3, 7-trimethylxanthine) in foods: a comprehensive review on consumption, functionality, safety, and regulatory matters. J Food Sci. 2010;75(3):R77-87.

14. Rivers WH, Webber HN. The action of caffeine on the capacity for muscular work. J Physiol. 1907;36(1):33.

15. Dunican IC, Higgins CC, Jones MJ, Clarke MW, Murray K, Dawson B, et al. Caffeine use in a super rugby game and its relationship to post-game sleep. Eur J Sport Sci. 2018;18(4):513-23.

16. Loureiro LM, Reis CE, da Costa TH. Effects of coffee components on muscle glycogen recovery: a systematic review. Int J Sport Nutr Exerc Metab. 2018;28(3):284-93.

17. Chen HY, Chen YC, Tung K, Chao HH, Wang HS. Effects of caffeine and sex on muscle performance and delayed onset muscle soreness after exercise-induced muscle damage: a double-blind randomized trial. J Appl Physiol. 2019;127(3):798-805.

18. Duncan MJ, Oxford SW. The effect of caffeine ingestion on mood state and bench press performance to failure. J Strength Cond Res. 2011;25(1):178-85.

19. Rothschild JA, Bishop DJ. Effects of dietary supplements on adaptations to endurance training. Sports Med. 2020;50(1):25-53.

20. Pickering C, Kiely J. What should we do about habitual caffeine use in athletes? Sports Med. 2019;49(6):833-42.

21. Lara B, Ruiz-Moreno C, Salinero JJ, Del Coso J. Time course of tolerance to the performance benefits of caffeine. PloS One. 2019;14(1):e0210275.

22. Burke LM. Caffeine and sports performance. Appl Physiol Nutr Metab. 2008;33(6):1319-34. 
23. Stuart GR, Hopkins WG, Cook C, Cairns SP. Multiple effects of caffeine on simulated high-intensity team-sport performance. Med Sci Sports Exerc. 2005;37(11):1998.

24. Duncan MJ, Stanley M, Parkhouse N, Cook K, Smith M. Acute caffeine ingestion enhances strength performance and reduces perceived exertion and muscle pain perception during resistance exercise. Eur J Sport Sci. 2013;13(4):392-9.

25. Grgic J. Caffeine ingestion enhances Wingate performance: a meta-analysis. Eur J Sport Sci. 2018;18(2):219-25.

26. Grgic J, Mikulic P. Caffeine ingestion acutely enhances muscular strength and power but not muscular endurance in resistance-trained men. Eur J Sport Sci. 2017;17(8):1029-36.

27. Ganio MS, Klau JF, Casa DJ, Armstrong LE, Maresh CM. Effect of caffeine on sport-specific endurance performance: a systematic review. J Strength Cond Res. 2009;23(1):315-24.

28. Astorino TA, Roberson DW. Efficacy of acute caffeine ingestion for short-term high-intensity exercise performance: a systematic review. J Strength Cond Res. 2010;24(1):257-65.

29. Del Coso J, Pérez-López A, Abian-Vicen J, Salinero JJ, Lara B, Valadés D. Enhancing physical performance in male volleyball players with a caffeine-containing energy drink. Int J Sports Physiol Perform. 2014;9(6):1013-8.

30. Del Coso J, Portillo J, Muñoz G, Abián-Vicén J, Gonzalez-Millán C, Muñoz-Guerra J. Caffeinecontaining energy drink improves sprint performance during an international rugby sevens competition. Amino Acids. 2013;44(6):1511-9.

31. Del Coso J, Muñoz-Fernández VE, Muñoz G, Fernández-Elías VE, Ortega JF, Hamouti N, et al. Effects of a caffeine-containing energy drink on simulated soccer performance. PloS One. 2012;7(2):e31380.

32. Abian-Vicen J, Puente C, Salinero JJ, González-Millán C, Areces F, Munoz G, et al. A caffeinated energy drink improves jump performance in adolescent basketball players. Amino Acids. 2014;46(5):1333-41.

33. Lara B, Ruiz-Vicente D, Areces F, Abián-Vicén J, Salinero JJ, Gonzalez-Millán C, et al. Acute consumption of a caffeinated energy drink enhances aspects of performance in sprint swimmers. Br J Nutr. 2015;114(6):908-14.

34. Del Coso J, Muñoz G, Muñoz-Guerra J. Prevalence of caffeine use in elite athletes following its removal from the World Anti-Doping Agency list of banned substances. Appl Physiol Nutr Metab. 2011;36(4):555-61.

35. Desbrow B, Leveritt M. Awareness and use of caffeine by athletes competing at the 2005 Ironman Triathlon World Championships. Int J Sport Nutr Exer Metab. 2006;16(5):545-58.

36. Foskett A, Ali A, Gant N. Caffeine enhances cognitive function and skill performance during simulated soccer activity. Int J Sport Nutr Exerc Metab. 2009;19(4):410-23.

37. Lieberman HR, Tharion WJ, Shukitt-Hale B, Speckman KL, Tulley R. Effects of caffeine, sleep loss, and stress on cognitive performance and mood during US Navy SEAL training. Psychopharmacology. 2002;164(3):250-61. 
38. Cook CJ, Crewther BT, Kilduff LP, Drawer S, Gaviglio CM. Skill execution and sleep deprivation: effects of acute caffeine or creatine supplementation-a randomized placebo-controlled trial. J Int Society Sports Nutr. 2011;8(1):2.

39. Baker LB, Nuccio RP, Jeukendrup AE. Acute effects of dietary constituents on motor skill and cognitive performance in athletes. Nutr Rev. 2014;72(12):790-802.

40. Motl RW, O'Connor PJ, Dishman RK. Effect of caffeine on perceptions of leg muscle pain during moderate intensity cycling exercise. J Pain. 2003;4(6):316-21.

41. Charney DS, Heninger GR, Jatlow PI. Increased anxiogenic effects of caffeine in panic disorders. Arch Gen Psychiatry. 1985;42(3):233-43.

42. Pickering C, Kiely J. Are the current guidelines on caffeine use in sport optimal for everyone? Interindividual variation in caffeine ergogenicity, and a move towards personalised sports nutrition. Sports Med. 2018;48(1):7-16.

43. Drake C, Roehrs T, Shambroom J, Roth T. Caffeine effects on sleep taken 0,3 , or 6 hours before going to bed. J Clin Sleep Med. 2013;9(11):1195-200.

44. Pickering C, Grgic J. Caffeine and exercise: what next? Sports Med. 2019;49(7):1007-1030..

45. Burke LM. Practical issues in evidence-based use of performance supplements: supplement interactions, repeated use and individual responses. Sports Med. 2017;47(1):79-100.

46. Cole KJ, Costill DL, Starling RD, Goodpaster BH, Trappe SW, Fink WJ. Effect of caffeine ingestion on perception of effort and subsequent work production. Int J Sport Nutr Exerc Metab. 1996;6(1):1423.

47. Stadheim HK, Spencer M, Olsen R, Jensen J. Caffeine and performance over consecutive days of simulated competition. Med Sci Sports Exerc. 2014; 46(6);1787-96.

48. Bell DG, McLellan TM. Exercise endurance 1, 3, and $6 \mathrm{~h}$ after caffeine ingestion in caffeine users and nonusers. J Appl Physiol. 2002;93(4):1227-34.

49. Negaresh R, Del Coso J, Mokhtarzade M, Lima-Silva AE, Baker JS, Willems ME, et al. Effects of different dosages of caffeine administration on wrestling performance during a simulated tournament. Eur J Sport Sci. 2019;19(4):499-507.

50. Tunnicliffe JM, Erdman KA, Reimer RA, Lun V, Shearer J. Consumption of dietary caffeine and coffee in physically active populations: physiological interactions. Appl Physiol Nutr Metab. 2008;33(6):1301-10.

51. Hurley CF, Hatfield DL, Riebe DA. The effect of caffeine ingestion on delayed onset muscle soreness. J Strength Cond Res. 2013;27(11):3101-9.

52. Maridakis V, O’Connor PJ, Dudley GA, McCully KK. Caffeine attenuates delayed-onset muscle pain and force loss following eccentric exercise. J Pain. 2007;8(3):237-43.

53. Lieberman HR, Wurtman RJ, Emde GG, Roberts C, Coviella IL. The effects of low doses of caffeine on human performance and mood. Psychopharmacology. 1987;92(3):308-12.

54. Azevedo R, Silva-Cavalcante MD, Gualano B, Lima-Silva AE, Bertuzzi R. Effects of caffeine ingestion on endurance performance in mentally fatigued individuals. Eur J Appl Physiol. 2016;116(11-12):2293-303.

55. Graham TE. Caffeine and exercise. Sports Med. 2001;31(11):785-807. 
56. Malek MH, Housh TJ, Coburn JW, Beck TW. Effects of eight weeks of caffeine supplementation and endurance training on aerobic fitness and body composition. J Strength Cond Res. 2006;20(4):751.

57. Kemp JG, Eaton T, Jarvis S, Meehan D, Olcina G, Whyte DG. Caffeine improves strength gains in response to 6 weeks of resistance training. J Aus Strength Cond. 2013;20(1):48-50

58. Miwa S, Sugimoto N, Yamamoto N, Shirai T, Nishida H, Hayashi K, et al. Caffeine induces apoptosis of osteosarcoma cells by inhibiting AKT/mTOR/S6K, NF-кB and MAPK pathways. Anticancer Res. 2012;32(9):3643-9.

59. Wackerhage H, Schoenfeld BJ, Hamilton DL, Lehti M, Hulmi JJ. Stimuli and sensors that initiate skeletal muscle hypertrophy following resistance exercise. J Appl Physiol 2019;126(1):30-43

60. Moore TM, Mortensen XM, Ashby CK, Harris AM, Kump KJ, Laird DW, et al. The effect of caffeine on skeletal muscle anabolic signaling and hypertrophy. Appl Physiol Nutr Metab. 2017;42(6):621-9.

61. Bui S. The effects of caffeine intake on muscle protein synthesis and the change in lean mass following resistance exercise [doctoral dissertation]. College Station: Texas A\&M University; 2015.

62. McConell GK, Ng GP, Phillips M, Ruan Z, Macaulay SL, Wadley GD. Central role of nitric oxide synthase in AICAR and caffeine-induced mitochondrial biogenesis in L6 myocytes. J Appl Physiol. 2010;108(3):589-95.

63. Fredholm BB. Are the actions of methylxanthines due to antagonism of adenosine. Trends Pharmacol Sci. 1980;1:129-32.

64. Sökmen B, Armstrong LE, Kraemer WJ, Casa DJ, Dias JC, Judelson DA, Maresh CM. Caffeine use in sports: considerations for the athlete. J Strength Cond Res. 2008;22(3):978-86.

65. Dodd SL, Brooks E, Powers SK, Tulley R. The effects of caffeine on graded exercise performance in caffeine naive versus habituated subjects. Eur J Appl Physiol Occup Physiol. 1991;62(6):424-9.

66. Gonçalves LD, Painelli VD, Yamaguchi G, Oliveira LF, Saunders B, da Silva RP, et al. Dispelling the myth that habitual caffeine consumption influences the performance response to acute caffeine supplementation. J Appl Physiol. 2017;123(1):213-20.

67. Sabol F, Grgic J, Mikulic P. The effects of 3 different doses of caffeine on jumping and throwing performance: a randomized, double-blind, crossover study. Int J Sports Physiol Perform. 2019;14(9):1170-7.

68. Beaumont R, Cordery P, Funnell M, Mears S, James L, Watson P. Chronic ingestion of a low dose of caffeine induces tolerance to the performance benefits of caffeine. J Sports Sci. 2017;35(19):1920-7.

69. Bell DG, McLellan TM. Effect of repeated caffeine ingestion on repeated exhaustive exercise endurance. Med Sci Sports Exerc. 2003;35(8):1348-54.

70. Fisher SM, McMurray RG, Berry M, Mar MH, Forsythe WA. Influence of caffeine on exercise performance in habitual caffeine users. Int J Sports Med. 1986;7(05):276-80.

71. Irwin C, Desbrow B, Ellis A, O'Keeffe B, Grant G, Leveritt M. Caffeine withdrawal and high-intensity endurance cycling performance. J Sports Sci. 2011;29(5):509-15.

72. Van Soeren MH, Graham TE. Effect of caffeine on metabolism, exercise endurance, and catecholamine responses after withdrawal. J Appl Physiol. 1998;85(4):1493-501. 
74. Juliano LM, Griffiths RR. A critical review of caffeine withdrawal: empirical validation of symptoms and signs, incidence, severity, and associated features. Psychopharmacology. 2004;176(1):1-29.

551

552

553

554

555

556

557

558

559

560

561

562

563

564

565

566

567

568

569

570

571

572

573

574

575

576

577

578

579

580

581

582

583

584

585

586
75. James JE, Rogers PJ. Effects of caffeine on performance and mood: withdrawal reversal is the most plausible explanation. Psychopharmacology. 2005;182(1):1-8.

76. Beedie CJ, Stuart EM, Coleman DA, Foad AJ. Placebo effects of caffeine on cycling performance. Med Sci Sports Exerc. 2006;38(12):2159-64.

77. Foad AJ, Beedie CJ, Coleman DA. Pharmacological and psychological effects of caffeine ingestion in 40-km cycling performance. Med Sci Sports Exerc. 2008;40(1):158-65.

78. Pollo A, Carlino E, Benedetti F. The top-down influence of ergogenic placebos on muscle work and fatigue. Eur J Neurosci. 2008;28(2):379-88.

79. Saunders B, de Oliveira LF, da Silva RP, de Salles Painelli V, Gonçalves LS, Yamaguchi G, et al. Placebo in sports nutrition: a proof-of-principle study involving caffeine supplementation. Scand J Med Sci Sports. 2017;27(11):1240-7.

80. Grgic J, Venier S, Mikulic P. Both caffeine and placebo improve vertical jump performance compared with a nonsupplemented control condition. Int J Sports Physiol Perform. 2020; DOI: 10.1123/ijspp.2019-1028

81. Pickering C. Are caffeine's performance-enhancing effects partially driven by its bitter taste? Med Hypotheses. 2019;131:109301.

82. Best R, McDonald K, Hurst P, Pickering C. Can taste be ergogenic? Eur J Nutr. 2020; doi: 10.1007/s00394-020-02274-5

83. Beedie CJ. Placebo effects in competitive sport: qualitative data. J Sports Sci Med. 2007;6(1):21.

84. Goldstein ER, Ziegenfuss T, Kalman D, Kreider R, Campbell B, Wilborn C, et al. International society of sports nutrition position stand: caffeine and performance. J Int Soc Sports Nutr. 2010;7(1):5.

85. Guest N, Corey P, Vescovi J, El-Sohemy A. Caffeine, CYP1A2 genotype, and endurance performance in athletes. Med Sci Sports Exerc. 2018;50(8):1570-8.

86. Grgic J, Pickering C, Bishop DJ, Schoenfeld BJ, Mikulic P, Pedisic Z. CYP1A2 genotype and acute effects of caffeine on resistance exercise, jumping, and sprinting performance. J Int Soc Sports Nutr. 2020;17(1):21.

87. Spineli H, Pinto MP, Dos Santos BP, Lima-Silva AE, Bertuzzi R, Gitai DLG, de Araujo GG. Caffeine improvements various aspects of athletic performance in adolescents independent of their $163 \mathrm{C}>\mathrm{A}$ CYP1A2 genotypes. Scand J Med Sci Sports. 2020; https://doi.org/10.1111/sms.13749

88. Tallis J, James RS, Cox VM, Duncan MJ. Is the ergogenicity of caffeine affected by increasing age? The direct effect of a physiological concentration of caffeine on the power output of maximally stimulated EDL and diaphragm muscle isolated from the mouse. J Nutr Health Aging. 2017;21(4):4408.

89. Boyett JC, Giersch GE, Womack CJ, Saunders MJ, Hughey CA, Daley HM, Luden ND. Time of day and training status both impact the efficacy of caffeine for short duration cycling performance.

Nutrients. 2016;8(10):639. 
90. Mora-Rodríguez R, Pallarés JG, López-Gullón JM, López-Samanes Á, Fernández-Elías VE, Ortega JF. Improvements on neuromuscular performance with caffeine ingestion depend on the time-of-day. J Sci Med Sport. 2015;18(3):338-42.

91. Pataky MW, Womack CJ, Saunders MJ, Goffe JL, D'lugos AC, El-Sohemy A, Luden ND. Caffeine and 3-km cycling performance: Effects of mouth rinsing, genotype, and time of day. Scand J Med Sci Sports. 2016;26(6):613-9.

92. Collomp K, Ahmaidi S, Chatard JC, Audran M, Prefaut C. Benefits of caffeine ingestion on sprint performance in trained and untrained swimmers. Eur J Appl Physiol Occup Physiol. 1992;64(4):37780.

93. Talanian JL, Spriet LL. Low doses of caffeine late in exercise improve cycling time trial performance. Appl Physiol Nutr Metab. 2016;41(8):850-5.

94. Spriet LL. Exercise and sport performance with low doses of caffeine. Sports Med. 2014;44(2):175-84.

95. Stellingwerff T, Bovim IM, Whitfield J. Contemporary nutrition interventions to optimize performance in middle-distance runners. Int J Sport Nutr Exerc Metab. 2019;29(2):106-16.

96. Burke LM, Jeukendrup AE, Jones AM, Mooses M. Contemporary nutrition strategies to optimize performance in distance runners and race walkers. Int J Sport Nutr Exerc Metab. 2019;29(2):117-29.

97. Kasper AM, Cocking S, Cockayne M, Barnard M, Tench J, Parker L, et al. Carbohydrate mouth rinse and caffeine improves high-intensity interval running capacity when carbohydrate restricted. Eur J Sport Sci. 2016;16(5):560-8.

98. Kizzi J, Sum A, Houston FE, Hayes LD. Influence of a caffeine mouth rinse on sprint cycling following glycogen depletion. Eur J Sport Sci. 2016;16(8):1087-94.

99. Schubert MM, Irwin C, Seay RF, Clarke HE, Allegro D, Desbrow B. Caffeine, coffee, and appetite control: A review. Int J Food Sci Nutr 2017;68(8):901-912.

100.Stadheim HK, Nossum EM, Olsen R, Spencer M, Jensen J. Caffeine improves performance in double poling during acute exposure to 2,000-m altitude. J Appl Physiol. 2015;119(12):1501-9.

101.Zee PC, Goldstein CA. Treatment of shift work disorder and jet lag. Curr Treat Options Neurol. 2010;12(5):396-411.

102.Pickering C. Caffeine, CYP1A2 genotype, and sports performance: is timing important? Ir J Med Sci. 2019;188(1):349-50.

103. Wickham KA, Spriet LL. Administration of caffeine in alternate forms. Sports Med. 2018;48(1):79-91. 104.Pickering C, Kiely J. Are low doses of caffeine as ergogenic as higher doses? A critical review highlighting the need for comparison to current best practice in caffeine research. Nutrition. 2019;6768:110535.

105.Conger SA, Warren GL, Hardy MA, Millard-Stafford ML. Does caffeine added to carbohydrate provide additional ergogenic benefit for endurance? Int J Sport Nutr Exerc Metab. 2011;21(1):71-84.

106.Grgic J. Effects of combining caffeine and sodium bicarbonate on exercise performance: a review with suggestions for further research. Journal of Dietary Supplements. 2020: doi:10.1080/19390211.2020.1783422

107.Pickering C, Grgic J. Is coffee a useful source of caffeine preexercise? Int J Sport Nutr Exerc Metab. 2019; doi: 10.1123/ijsnem.2019-0092 

from retail coffee outlets. Food Chem Toxicol. 2007;45(9):1588-92. commercial coffee and coffee-flavoured milk. J Food Composition Analysis. 2012;28(2):114-8. 110.Desbrow B, Hall S, Irwin C. Caffeine content of Nespresso® pod coffee. Nutr Health. 2019;25(1):3-7.

111.Boekema J, Samsom M, van Berge Henegouwen GP, Smout P. Coffee and gastrointestinal function: facts and fiction: a review. Scand J Gastroenterol. 1999;34(230):35-9. J Sport Nutr Exerc Metab. 2015;25(6):607-23.

636 